\title{
Ionic Liquids and their Polymers in Lithium-Sulfur Batteries
}

\author{
Elinor Josef, ${ }^{[\mathrm{a}]}$ Yajing Yan, ${ }^{[\mathrm{b}]}$ Marian Cristian Stan, ${ }^{[\mathrm{c}]}$ Julia Wellmann, ${ }^{[\mathrm{cc}]}$ Alen Vizintin, ${ }^{[\mathrm{d}]}$ Martin Winter, ${ }^{[\mathrm{c}, \mathrm{e}]}$ \\ Patrik Johansson, ${ }^{[\mathrm{b}, \mathrm{f}]}$ Robert Dominko, ${ }^{[\mathrm{d}, \mathrm{f}]}$ and Ryan Guterman*${ }^{* \mathrm{a}]}$
}

\begin{abstract}
Future optimized lithium-sulfur batteries may promise higher energy densities than the current standard. However, there are many barriers which hinder their commercialization. In this review we describe how ionic liquids (ILs) and their polymers are utilized in different components of the battery to address some of these issues. For example, IL-based electrolytes have the potential to reduce the solubility of polysulfides compared to conventional organic electrolytes. Polymerizing ILs directly on the
\end{abstract}

surface of the Li-metal anode is suggested as an approach to protect the surface of this electrode. Finally, using poly(ionic liquids) (PILs) as binders for the cathode active material may increase the performance of the cathode as compared to polyvinylidene difluoride (PVdF) and could inhibit swellinginduced degradation. These results demonstrate the advantages of ILs and their polymers for improving the performance of Li-S batteries.

Keywords: Lithium-sulfur batteries · ionic liquids · poly(ionic liquids) $\cdot$ Li-metal anode $\cdot$ electrolytes

\section{Introduction}

The development of sustainable and clean energy storage solutions is crucial for replacing fossil fuels, which rely on depleting sources. Efficient, cheap, and light rechargeable batteries provide an opportunity for practical electric vehicles (xEVs), grid energy storage systems, and portable electronics and is imperative for future technologies. ${ }^{[1]}$ Currently the most widely used rechargeable batteries are of the lithium-ion (Liion) type, which was commercialized by Sony in the early 1990 s. ${ }^{[2]}$ After much R\&D, these batteries, most specifically the cathodes, have reached their maximum energy density that can be provided, limiting their impact on the automotive market $(\mathrm{xEV})$ since the estimated driving range required for BEVs $(500 \mathrm{~km})$ cannot be met yet. ${ }^{[3]}$ Thus, there is a pursuit for batteries with higher energy densities. Lithium-sulfur $(\mathrm{Li}-\mathrm{S})$ batteries are among the most promising candidates to replace lithium ion batteries (LIB), much due to their in theory higher energy density, when only the active materials alone are considered, to be approximately $1675 \mathrm{mAhg}^{-1}{ }^{[4,5]}$ In practice, at cell level, the targeted energy density for $\mathrm{Li}-\mathrm{S}$ batteries is often set to $c a .322 \mathrm{mAhg}^{-1}$, a value that if reached would grant their commercial success. Moreover, the use of highly abundant sulfur $\left(\mathrm{S}_{8}\right)$ in the cathode makes the battery design more cost effective in comparison to the transition metal based oxides used in LIBs. ${ }^{[6]}$ Despite this fact, there are other obstacles that hinder the application of $\mathrm{Li}-\mathrm{S}$ batteries. $^{[3,7-12]}$

A typical $\mathrm{Li}-\mathrm{S}$ battery is composed of a $\mathrm{Li}$-metal anode, $\mathrm{S}_{8} / \mathrm{C}$ composite cathode (most often the $\mathrm{C}$ is a porous carbon host), a separator, and a liquid or solid electrolyte (Figure 1). During the discharge process the $S_{8}$ is reduced from elemental $\mathrm{S}_{8}$ to $\mathrm{Li}_{2} \mathrm{~S}$ in a stepwise fashion through various polysulfide intermediates. ${ }^{[13]}$ One of the most critical issue with the described reaction, is that the polysulfide intermediates are highly soluble in the organic solvents commonly used in the electrolytes. This high solubility causes irreversible migration of the polysulfide from the cathode through the separator to the anode. Hence active material is lost from the cathode and the anode is contaminated, causing poor Coulombic efficiencies (CE) during cycling and a high self-discharge rate. ${ }^{[11]}$ This phenomenon is refered to as "lithium polysulfide shuttle mechanism". Another major obstacle is volume changes at the cathode, which is a result of up to an $80 \%$ expansion of $\mathrm{S}_{8}$ to $\mathrm{Li}_{2} \mathrm{~S}$ during the charge-discharge process, shortening the battery's lifetime. ${ }^{[8-10,14]}$ Such volume change disrupts electrical contacts within the cathode leading to cell failure. ${ }^{[12]}$ Side reactions between the Li-metal anode and solubilized poly-

[a] E. Josef, R. Guterman

Max Planck Institute of Colloids and Interfaces, Department of Colloid Chemistry, Am Mühlenberg 1, 14476 Potsdam, Germany

E-mail: elinor.josef@mpikg.mpg.de

[b] Y. Yan, P. Johansson

Department of Physics, Chalmers University of Technology, SE41296 Göteborg, Sweden

[c] M. C. Stan, J. Wellmann, M. Winter

MEET Battery Research Center, University of Münster, Corrennstrasse 46, 48149 Münster, Germany

[d] A. Vizintin, R. Dominko

National Institute of Chemistry, Hajdrihova 19, 1000 Ljubljana, Slovenia Faculty of Chemistry and Chemical Technology, University of Ljubljana, Večna pot 113, 1000 Ljubljana, Slovenia

[e] M. Winter

Helmholz-Institute Münster (HI MS), IEK-12 of Forschungszentrum Jülich, Corrensstrasse 46, 48149 Münster, Germany

[f] P. Johansson, R. Dominko

ALISTORE-European Research Institute, CNRS FR 3104, Hub de l'Energie, Rue Baudelocque, 80039 Amiens, France

Supporting information for this article is available on the WWW under https://doi.org/10.1002/ijch.201800159 


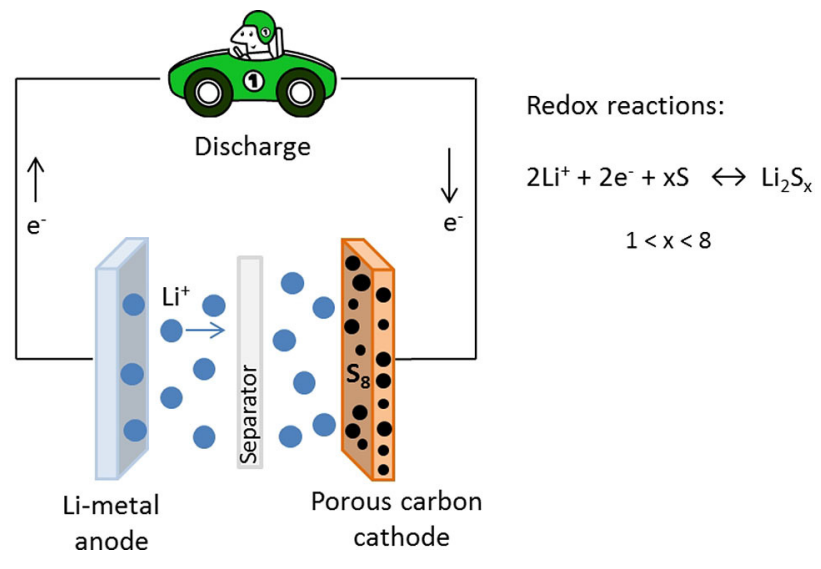

Figure 1. Scheme of a Li-S battery

sulfides also contribute to low cycling stability. ${ }^{[15]}$ Finally, the low electrical and ionic conductivity of $\mathrm{S}_{8}$ and the final discharge product, $\mathrm{Li}_{2} \mathrm{~S}$, constrains the efficient use of the active materials. In addition to the problem associated with the $\mathrm{S}_{8} / \mathrm{C}$ composite cathode, the degradation of the Li-metal anode is an equally major limiting factor for the commercialization of $\mathrm{Li}-\mathrm{S}$ batteries. On top of the chemical reaction of the dissolved polysulfides with the Li-metal anode, there is also uncontrolled lithium dendrite growth. ${ }^{[16]}$ Overcoming these numerous barriers relies on the development of new materials for each component of the battery, such as electrolytes, ${ }^{[14,17,18]}$ membranes, ${ }^{[19,20]}$ cathodes, ${ }^{[11,22]} \mathrm{S}_{8}$ impregnation techniques, ${ }^{[21]}$ and Li-metal surface protection. ${ }^{[23]}$ Utilization of a different electrolyte/solvent, with less solubility power towards the intermediate polysulfides, could reduce the shuttle effect.

One class of compounds that have shown remarkable versatility in batteries are ionic liquids (ILs), which are defined as totally dissociated (into ions) salts possessing a melting point lower than $100^{\circ} \mathrm{C}$. They typically have negligible volatility, good thermal/electrochemical stability, high ionic conductivity, and wide electrochemical window. For these reasons, they have been examined as electrolyte components for commercial cells. ${ }^{[24]}$ Moreover, ILs can be used as starting materials to produce poly(ionic liquids) (PILs) ${ }^{[25,26]}$ combining the beneficial properties of "normal" ILs with properties of polymers, such as mechanical stability and processability. This marriage of properties has initiated new research frontiers with broad applicability, for example the use of PILs as particles, membranes, and coatings. ${ }^{[27]}$ ILs and IL-derived materials have been investigated for a variety of functions in batteries, ${ }^{[27]}$ including fabrication of electrode materials, ${ }^{[24,28]}$ as electrolytes, ${ }^{[29,30]}$ as binders ${ }^{[31,32]}$ as artificial solid electrolyte interphase (a-SEI) layer to protect the Limetal anode, ${ }^{[33]}$ as coating to enhance the interfacial wettability and stability in solid electrolyte cells, ${ }^{[34]}$ and as medium or solvent in the preparation of battery components. ${ }^{[35]}$ In each of these cases, ILs were found to either modify or improve the working operation of the battery. Well-studied applications of ILs in $\mathrm{Li}-\mathrm{S}$ batteries include their use as a non-solvating electrolyte to suppress the polysulfide solubility, which improved the cycling stability, ${ }^{[36]}$ and as a modifier of the SEI, leading to improved performance. ${ }^{[37]}$

In this review, we reflect on previous and new results describing how ILs and their polymers can help mitigate some problems plaguing the development of $\mathrm{Li}-\mathrm{S}$ batteries. This includes implementing IL based electrolytes to reduce polysulfide solubility, coating of the Li-metal anode with PILs to offer surface protection, and using PIL as a cathode binder to improve cycling stability. Much of this work is the result of a collaboration between partners within the HELIS (High energy lithium sulphur cells and batteries) consortium, an EU H2020 funded project for the development $\mathrm{Li}-\mathrm{S}$ batteries for commercial applications. ${ }^{[6,11,14,38-42]}$

\section{Examples of ILs and PILs}

\subsection{IL Based Electrolytes}

The general requirements for an electrolyte in a battery are that it has good ionic conductivity for facile ion transport and low electrically conductivity to minimize self-discharge. In addition it should have a wide electrochemical stability window, be cheap and environmentally friendly. Electrolytes should also be non-toxic and environmentally friendly, and have thermal, mechanical, and electrochemical stability in a wide potential window. In addition they should avoid side reactions with the separator, electrodes and casing. ${ }^{[11]}$ The most common electrolytes today are based on organic solvents doped with lithium salts ${ }^{[43-45]}$ even though several other systems have also been considered, such as glass ceramics ${ }^{[46]}$ and polymer electrolytes. ${ }^{[47]}$ Among the organic solvent based electrolytes, a mixture of 1,3-dioxolane (DOL) and 1,2dimethoxyethane (DME) $(1: 1, \mathrm{v} / \mathrm{v})$ doped with the Li-salt LiN $\left(\mathrm{CF}_{3} \mathrm{SO}_{2}\right)_{2}$ (LiTFSI) has been widely used in laboratory scale Li-S battery cells, due to low viscosity and high ion conductivity. ${ }^{[48-50]}$ However, as for other types of Li-batteries electrolytes based on organic solvents, they present serious safety issues which are related to the solvents' volatility, manifested in low flash points and high flammability. ${ }^{[4,45]}$

Room temperature ionic liquids (RTILs) are a subclass of ILs, being liquids at room temperature. In recent years they have been highlighted as a base for safer electrolytes in $\mathrm{Li}$ batteries as well as for other electrochemical devices. ${ }^{[51]}$ Especially aprotic RTILs frequently show useful properties such as negligible volatility, low flammability, high thermal stability and acceptable conductivity. With the right combination of anion and cation they can also have a wide electrochemical window. ${ }^{[51-53]}$ Unlike molecular solvents, the solvent properties of ILs are dictated by the interplay of interactions of cations and anions such as Coulombic forces, van der Waals forces and hydrogen bonds, as well as their own chemical nature toward solutes. Since the solubilities of elemental $\mathrm{S}_{8}$ and lithium polysulfides strongly affect the $\mathrm{Li}-\mathrm{S}$ battery performance, the unique solvation behavior of ILs is an 
important property. Certain ILs based electrolytes have been found to suppress the solubility of all the redox-active species ( $\mathrm{S}_{8}$ and $\mathrm{Li}_{2} \mathrm{~S}_{\mathrm{m}}$, where $\mathrm{m}=2-8$ sulfur atoms in the polysulfide) in addition to having acceptable Li-ion conductivity. ${ }^{[36,54-57]}$ But despite their advantages, most IL based electrolytes show lower conductivities than conventional organic solvent based electrolytes, mostly due to their higher viscosities.

Guided by battery performance, safety and cost, extensive research of using IL based electrolytes with organic cosolvents (hybrids) has been conducted to optimize electrolytes for $\mathrm{Li}-\mathrm{S}$ battery systems. ${ }^{[58-62]}$ For example ether-based solvents with high polysulfide solubility exhibiting excellent electrochemical performance in $\mathrm{Li}-\mathrm{S}$ cells can be applied as part of binary or ternary electrolyte mixtures..$^{[63,64]}$ The combination of ILs and ether-based solvents as Li-S battery electrolyte matrices can create synergies counterbalancing their different physico-chemical properties. Electrolytes composed of ILs and ether-based solvents such as DME and tetra (ethylene glycol) dimethyl ether (TEGDME) have shown good cell performance. ${ }^{[45,65,66]}$ By studying the electrochemical response of various solvent ratios, lithium salt concentrations, and use of additives, it was concluded that the solvation ability of the electrolyte is the key factor in high electrochemical performance..$^{[45]}$

The solubility of lithium polysulfides in ILs is strongly dependent on the anionic structure. ${ }^{[29]}$ The stronger is the donor ability of an IL, the higher the solubility of lithium polysulfides. The IL N,N-diethyl-N-methyl-N-(2-methoxyethyl)ammonium bis((trifluoromethyl)sulfonyl) imide ([DEME] [TFSI]) as an electrolyte solvent in $\mathrm{Li}-\mathrm{S}$ batteries in comparison with the TEGDME solvent showed superior performance in terms of cycle stability and efficiency. ${ }^{[57]}$ [DEME][TFSI] has a low donor ability, which can significantly suppress the dissolution of lithium polysulfides, because of the weak Lewis basicity of the TFSI anion. ${ }^{[2]}$ The IL Nmethoxyethyl-N-methylpyrrolidinium bis(trifluoromethanesulfonyl) imide ([PYR $\left.\left.{ }_{1,201}\right][\mathrm{TFSI}]\right)$ has a similar structure with an alkoxy group, and was recently tested in a mixture with TEGDME. ${ }^{[67,68]}$ It was also shown that the performance of the ILs can be improved by cation functionalization ${ }^{[69]}$

In this chapter, we compare two ILs as electrolyte matrices for $\mathrm{Li}-\mathrm{S}$ batteries, where TFSI is the anion and the cations are N-butyl-N-methylpyrrolidinium ([PYR 14$]$ ) and $\left[\mathrm{PYR}_{1,201}\right]$ (Figure $2 \mathrm{a}$ and Figure $2 \mathrm{~b}$ ). The highly flexible alkoxy chains in the ether functionalized ILs provide the transport convenience for the adjacent molecules and hinder crystallization, ${ }^{[70]}$ which can raise the conductivity and the $\mathrm{Li}_{2} \mathrm{~S}_{\mathrm{m}}$ solubility of the IL based
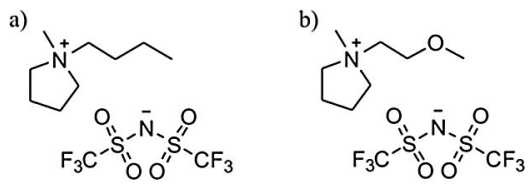

Figure 2. Chemical structures of the ILs: a) $\left[\mathrm{PYR}_{14}\right][\mathrm{TFSI}]$ and b) [PYR $_{1,201}$ ] [TFSI]. electrolyte. ${ }^{[71,72]}$ Operando UV-Vis spectroscopy was implemented to monitor the diffusion and dissolution of polysulfides.

Replacing an alkyl chain by an alkoxy chain in the IL cation shows a significant effect on the electrolyte viscosity ( $\eta$ ) (Table 1). Zheng et al. ${ }^{[70]}$ measured these to be highly variable and strongly dependent on the structures of the cation and ether moiety. The alkoxy chain effect on decreasing viscosity was ascribed to the increased free volume, which results from the high conformational flexibility of the ether moieties and provides more available holes for the mass transport. The alkoxy chain effect on decreasing the electrolyte viscosity, has its origin in the rod-like alkyl tail and $-\mathrm{CH}_{2}-$ spacer between the ether $\mathrm{O}$ atom and the cationic $\mathrm{N}$ atom. The ether-substituted RTILs possess high ion conductivities and the alkoxy chains also maintain the high electrochemical stabilities of pyrrolidinium and ammonium cation based RTILs. ${ }^{[70]}$

Table 1. Density $(\rho)$, conductivity $(\sigma)$ and viscosity $\left(\eta_{1}\right)$ for the ILs $\left[\mathrm{PYR}_{14}\right][\mathrm{TFSI}]$ and $[\mathrm{PYR} 1,2 \mathrm{O} 1][\mathrm{TFSI}]$ at $25^{\circ} \mathrm{C}$. The viscosities $\left(\eta_{2}\right)$ are for the IL based electrolytes.

\begin{tabular}{lllllll}
\hline lonic liquid & $\rho^{[a]}$ & $\eta_{1}{ }^{[b]}$ & $\sigma^{[c]}$ & $R^{[d]}$ & $\eta_{2}{ }^{[b]}$ & Name \\
\hline PYR $\left._{14}\right][T F S I]$ & 1.40 & 84.3 & 2.7 & $1: 9$ & 137 & E1 \\
PYR $\left._{1,201}\right][T F S I]$ & 1.46 & 53.0 & 3.8 & $1: 9$ & 64 & E2 \\
\hline
\end{tabular}

[a] $\left(\mathrm{g} \mathrm{cm}^{-3}\right)$. [b] (mPa s). [c] ( $\left.\mathrm{mS} \mathrm{cm}^{-1}\right)$. [d] R- $\mathrm{n}$ (LiTFSI): $\mathrm{n}$ (IL). Molar ratio of salt and IL (R) of electrolytes E1 and E2, and their measured viscosities $(\eta 2)$ at $25^{\circ} \mathrm{C}$.

Table 1 shows the density $(\rho)$, conductivity $(\sigma)$ and viscosity $\left(\eta_{1}\right)$ for $\left[\mathrm{PYR}_{14}\right][\mathrm{TFSI}]$ and, $\left[\mathrm{PYR}_{1,201}\right]$ [TFSI] ILs at $25^{\circ} \mathrm{C}$. Two binary IL based electrolytes were made by dissolving LiTFSI in a molar ratio of 1:9 salt to IL: LiTFSI/ $\left[\mathrm{PYR}_{14}\right]$ [TFSI] (E1) and LiTFSI/[PYR $\left.{ }_{1,201}\right]$ [TFSI] (E2). Locally coordination of Li-ions with two TFSI-anions and formation of oligomeric species have been reported, owing to the strong Lewis acidity of the Li-ions. ${ }^{[73,74]}$ The complex formation brings on an increased viscosity $\left(\eta_{2}\right)$ (Table 1$)$ and a consequent decrease in the ionic conductivity. ${ }^{[57]}$

Figure 3a shows the cycling performance of both IL based electrolytes - and some major and substantial differences. E2 with its functionalized anion group had a higher initial specific capacity, $c a .500 \mathrm{mAhg}^{-1}$ for the first 5 cycles and increasing up to the $25^{\text {th }}$ cycle after which it starts dropping and after 100 cycles reaches $280 \mathrm{mAh} \mathrm{g}^{-1}$. In contrast, E1 showed a lower initial capacity, ca. $300 \mathrm{mAh} \mathrm{g}^{-1}$, which slowly but constantly decreased and after 100 cycles reached $180 \mathrm{mAhg}^{-1}$. The worse performance of $\mathrm{E} 1$ can be attributed to lower sulfur utilization due to its higher viscosity and lower ion conductivity. The CE of E2 was continuously stable at almost $99 \%$, while it was over $100 \%$ for E1 for the first 20 cycles, possibly attributable to electrolyte decomposition and SEI formation. The discharge/charge curves show differences already for the first cycle for both electrolytes (Figure 3b) - 
a)
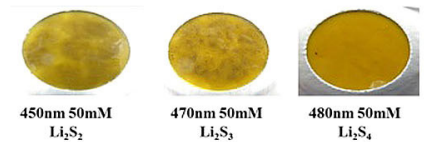

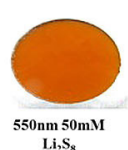

b)

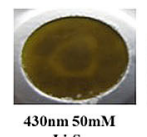

$\mathrm{Li}_{2} \mathrm{~S}_{2}$

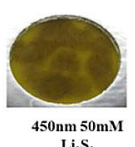

$\mathrm{Li}_{2} \mathrm{~S}_{3}$

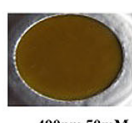

$\underset{\mathrm{Li}_{2} \mathrm{~S}_{4}}{490 \mathrm{~mm}}$

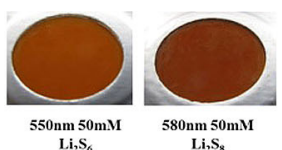

EI - PYR TFSI c)

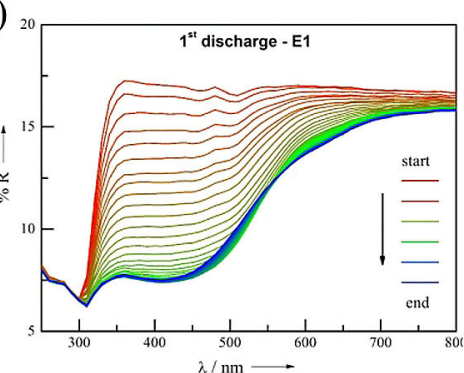

f)

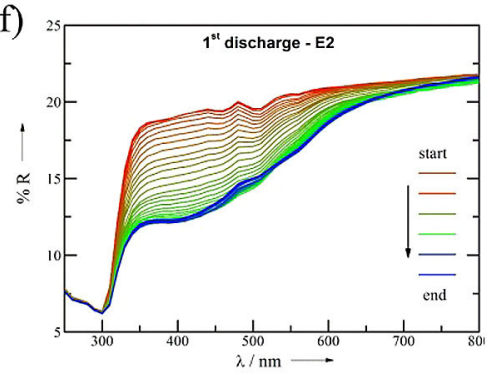

d)

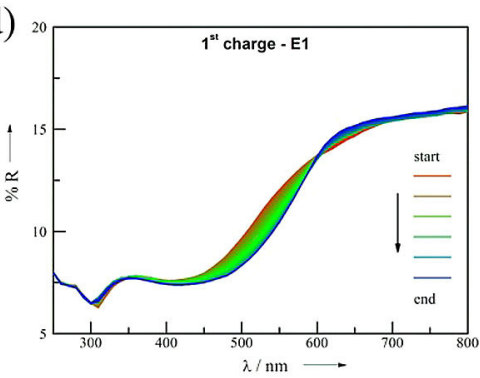

g)

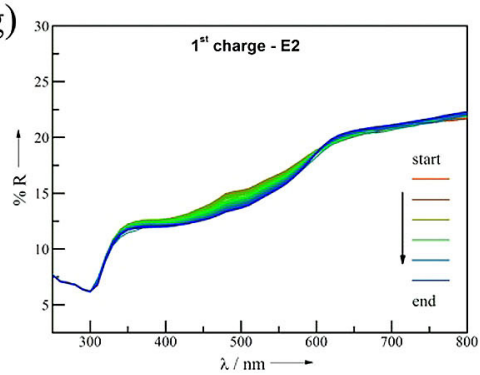

e)

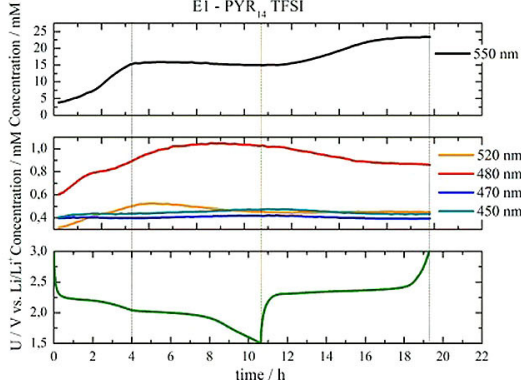

h)

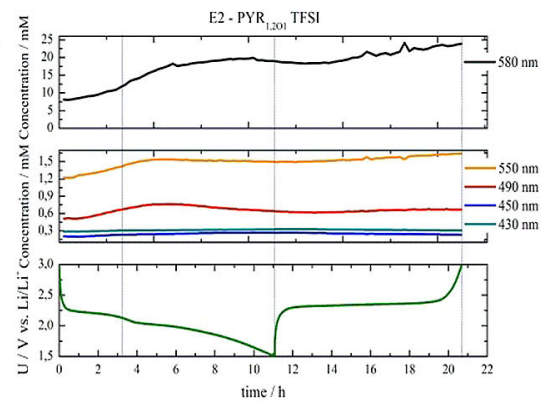

Figure 3. Photos of catholytes made from the two IL based electrolytes: (a) E1 and (b) E2. UV-Vis spectra measured in two Li-S batteries during (c) first charging, (d) first discharging, (e) obtained deconvolution curves for the El electrolyte and during (f) first charging, (g) first discharging, (h) obtained deconvolution curves for the E2 electrolyte.

especially the polarization was lower for E2. During the cycling, the $100^{\text {th }}$ cycles, the polarization remains almost unchanged. Another difference is the shapes of the $1^{\text {st }}$ cycle discharge/charge curves, where E2 shows two typical Li-S cell voltage plateaus at ca. 2.25 and $2.05 \mathrm{~V}$ in the discharge curve, while the charge curve exhibits only one plateau at $2.40 \mathrm{~V}$. In contrast, E1 has only one single discharge plateau at $2.15 \mathrm{~V}$.

In order to examine the diffusion and dissolution of polysulfides in the E1 and E2 electrolytes, we performed operando UV-Vis spectroscopy during the $1^{\text {st }}$ discharge/charge cycle. The configuration, assembly procedure, and measurement principles of our operando UV-Vis spectroscopy set-up and experiments have been provided previously. ${ }^{[75,76]}$ The interactions between polysulfides and the UV-Vis radiation depend on the length of the polysulfide chain, on the alkali metal, and on the electrolyte in which the polysulfides are dissolved. Since this was the first time we measured on the IL based electrolytes E1 and E2, any possible differences were first visually inspected. In addition, the catholytes containing the same molar concentration of different polysulfides were compared (Figure 4a,b).

Based on the visual inspection, we suggest that the solubility of short chain polysulfides in both E1 and E2 is very low, since we were not able to completely dissolve poly- sulfides prepared with low stoichiometric ratio between lithium and sulfur - seen as non-homogenous color distribution. The electrolytes also show differences in the coordination of the IL with the dissolved polysulfides, since the color of the same composition in the two electrolytes are different. For this reason, a UV-Vis calibration curve was prepared for each pair of polysulfide-electrolyte The reflections at selected wavelengths represent different sulfur/lithium ratios which were obtained from the chemically synthesized polysulfides. By using the same procedure as in our recent work, ${ }^{[76]}$ we measured UV-Vis spectra of all catholytes - which then were normalized and the reflectance at preselected wavelengths were used to construct calibration curves. The linear dependence between the normalized reflectance and the natural logarithm of the concentration was used to recalculate polysulfide concentrations in the separator during $\mathrm{Li}-\mathrm{S}$ battery discharge and charge.

Figure 3c,d,f,g show sets of operando UV-Vis spectra measured during $1^{\text {st }}$ discharge and $1^{\text {st }}$ charge for the E1 and E2 electrolytes. Red curves of the UV-Vis spectra represent the start and end of the half cycle, respectively, either charge or discharge. A difference can be detected between E1 and E2 in the appearance of long-chain, mid-chain and short-chain polysulfides. First, the signal from long-chain polysulfides in the first discharge cycle in E1 is less intense than for E2, but 

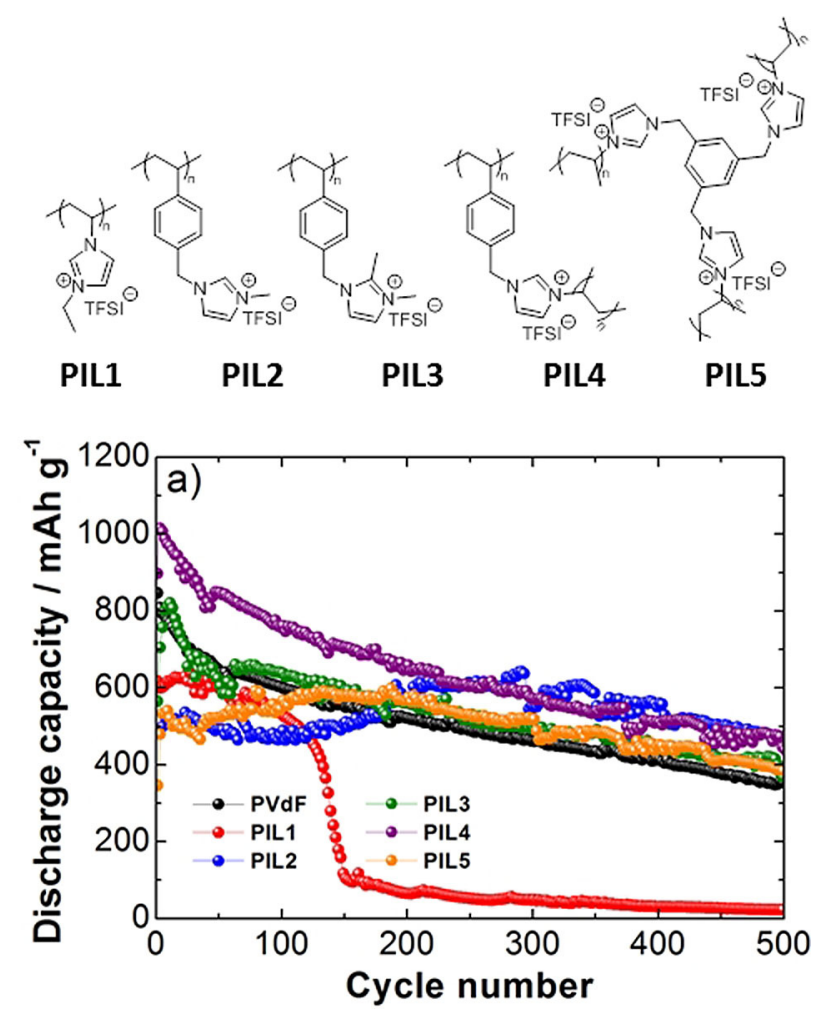

Figure 4. PIL binders examined for use in LI-S batteries (top) and the resulting cell discharge capacities for cycling at $\mathrm{C} / 5 \mathrm{C}$-rate (bottom).

the signal for mid- and short-chain polysulfides is less intense for E2. Less intense reflectance during the battery discharge and charge are directly correlated to a lower amount of polysulfides. This difference can be more precisely evaluated after spectral deconvolution, using a published procedure. ${ }^{[76]}$ In the $1^{\text {st }}$ cycle we observed a similar trend of polysulfide formation in both E1 and E2 which are quite different compared to organic solvent based electrolytes. ${ }^{[75,76]}$ As shown in Figure 3e,h, long chain polysulfides (black curves) appear first and their concentration is almost constant from the end of the high voltage plateau to the end of discharging, and the maximum concentration is reached at the end of charging. The formations of mid-chain polysulfides follow the same evolution, but at much lower concentrations, and E2 has lower concentrations than E1. The concentration of short-chain polysulfides is almost the same throughout the cycle from the beginning of discharge until the end of the charge cycle. There is thus no evolution of short-chain polysulfides during cycling of a $\mathrm{Li}-\mathrm{S}$ cell when using E1 or E2 electrolytes, and the concentration of these polysulfides is about an order of magnitude lower than reported for organic solvent based electrolytes. ${ }^{[75,76]}$ The lower concentration of short- and midchain polysulfides in the cell with the E2 electrolyte confirms the lower solubility of polysulfides in $\left[\mathrm{PYR}_{1,2 \mathrm{O} 1}\right][\mathrm{TFSI}]$ as compared to the $\left[\mathrm{PYR}_{14}\right][\mathrm{TFSI}] \mathrm{IL}$, again strengthening the connection between solubility of the polysulfides and the anion structure. The low solubility of $\mathrm{Li}_{2} \mathrm{~S}_{\mathrm{m}}$ in the IL based electrolytes can also be explained in terms of the donor ability of the electrolytes - the weaker is the donor ability the lower the solubility of lithium polysulfides. ${ }^{[29]}$

\subsection{Poly (Ionic Liquid)s as Binders}

Cathode binders are responsible for gluing together the cathode components (active materials and conductive additives) and comprise a significant portion of the total weight of the cell $(5-10 \mathrm{wt} \%){ }^{[11]}$ Despite this, the role of binders in the operation of the battery has garnered less attention since polyvinylidene difluoride $(\mathrm{PVdF})$ appears to provide sufficient performance. ${ }^{[77-80]} \mathrm{PVdF}$ is currently the standard for LIB technology and is routinely used for its chemical inertness and availability. However, PVdF does not support the particularly large volume expansion that occurs in $\mathrm{Li}-\mathrm{S}$ batteries during charge and discharge. Utilizing an active binder that can accommodate this volume expansion while contributing to the performance of the battery could help to accelerate the development of $\mathrm{Li}-\mathrm{S}$ batteries as a practical alternative to current battery technologies. PILs with their high electrochemical stability, ion conductivity, and good processability are well suited for electrochemical applications. ${ }^{[81]}$ Their high stability was found to be advantageous for use as electrolytes themselves ${ }^{[82]}$ or as binders in LIBs. ${ }^{[31,83]}$ It was found that homopolymer PILs were capable of wrapping the powder components while still allowing for Li-ions to flow, thus improving cycling stability. ${ }^{[31]}$ This in contrast to nanoparticle PILs which were found to operate by allowing electrolyte to permeate the free volume. ${ }^{[83]}$ During cycling, these nanoparticles would maintain contacts between the conductive components while permitting the flow of electrolyte. While PILs have been examined for use in a variety of different electrochemical devices and batteries, only a few studies have been conducted for the use of PILs in $\mathrm{Li}-\mathrm{S}$ batteries. ${ }^{[84-86]}$ Helms et al. compared the performance of a $\mathrm{Li}-\mathrm{S}$ battery where the binder was either PVdF or a PIL with a PYR-based backbone and TFSI as a counter-ion. They found strong evidence that the backbone of the cationic PIL could interact with the hydrophobic and electrolyte soluble polysulfides, which could prevent their diffusion from the cathode, leading in turn to improved cycling stability. ${ }^{[86]}$ It was also found that employing a mobile anion, TFSI, enhances the reaction kinetics for $\mathrm{S} / \mathrm{Li}_{2} \mathrm{~S}$ interconversion. ${ }^{[87]}$ However, no study has been conducted to compare the effect of different cationic polymers or PILs.

Recently we examined the performance of 5 different PILs as cathode binders in $\mathrm{Li}-\mathrm{S}$ batteries, including three as linear homopolymers and two as nanoparticles (Figure 4). ${ }^{[88]}$ With the exception of PIL1, all PIL binders were similar or better than PVdF. The similar performances of PIL2 and PIL3 indicates that methyl protection at the $\mathrm{C} 2$ position is not particularly important, unlike in Li-ion batteries which benefits from $\mathrm{C} 2$ protection. ${ }^{[20]}$ This effect likely due to the 
lower operating voltages in $\mathrm{Li}-\mathrm{S}$ vs. Li-ion batteries and indicates that greater tolerances for PIL structures is possible. The Li-S cell with PIL4 attained the highest discharge capacity of $1015 \mathrm{mAhg}^{-1}$ after 3 cycles and was the highest among the binders tested. The decrease in cycling capacity was investigated by comparing the contributions of the sulfur reduction into long- and mid-chain polysulfides (high-voltage plateau) to the equilibrium between polysulfides and precipitated $\mathrm{Li}_{2} \mathrm{~S}$ (low-voltage pleateau) in the voltage profile (Table S-1). ${ }^{[6,89,90]}$ For PVdF the capacity degradation is about the same at both the high and the low voltage plateaus, correlating with the loss of sulfur. For PIL4, the reduction of sulfur to $\mathrm{Li}_{2} \mathrm{~S}_{4}$ was found to be more efficient upon prolonged discharge-charge cycling. Interestingly, for PIL2 and PIL5, the contribution of the high-voltage plateau was initially high, but decreased over time.

This demonstrates an initial reduction from $\mathrm{Li}_{2} \mathrm{~S}_{4}$ to $\mathrm{Li}_{2} \mathrm{~S}$, and indicates an initial kinetics limitation. These results demonstrate that PILs will participate in and alter the cycling process while influencing the electrochemistry, unlike PVdF which is more passive.

The effect of the PIL binders on the cathode morphology was also determined by post mortem SEM of disassembled cell cathodes. SEM images of freshly prepared, discharged (1.5 V), and charged (3 V) cathodes containing PVdF, PIL2, and PIL4 are shown in Figure 5. The fresh cathodes all looked similar with a porous structure and interconnected sulfurimpregnated carbon particles. However, large differences and changes were observed for the discharged cathodes with significant divergence between the PIL and PVdF binders. The discharged cathode with PVdF possesses blocked pores due to the crystallization of $\mathrm{Li}_{2} \mathrm{~S}$ on the cathode surface. When charged, the open porosity is re-established due to $\mathrm{Li}_{2} \mathrm{~S}$ consumption and the reformation of $\mathrm{S}_{8}$. SEM images of the discharged cathodes with PIL2 and PIL4, however, were similar to each other with a "swelled particle" structure

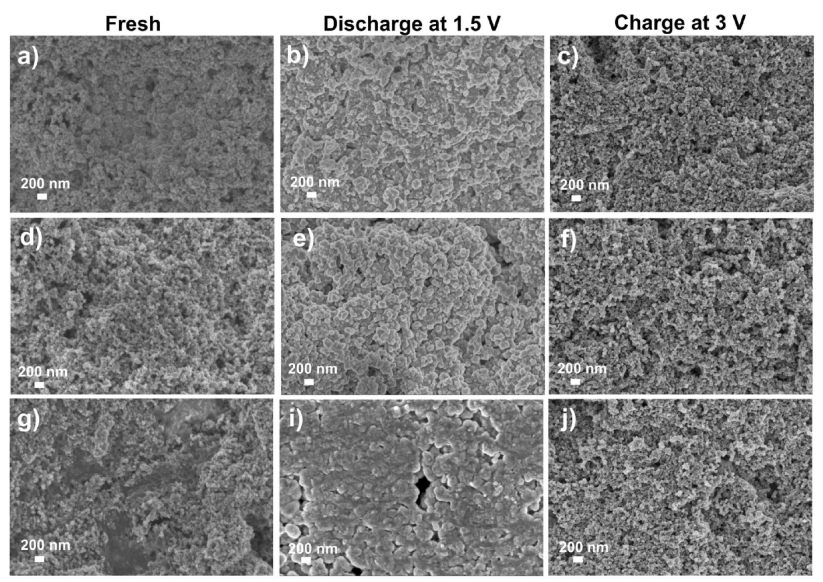

Figure 5. SEM micrographs with high magnification top-view for fresh, discharged at $1.5 \mathrm{~V}$ and charged at $3.0 \mathrm{~V}$ sulfur cathodes with a) to c) PVdF binder, d) and f) PIL2, and g) and j) PIL4. containing open pores. This is in stark contrast to the discharged cathode containing PVdF binder, which appears to have filled pores and no "swelling". This indicates that the growth of $\mathrm{Li}_{2} \mathrm{~S}$ is likely different in the presence of PIL binder and that the improved cycling is derived from this interaction. This can be further explained by the studies of Welton et al. ${ }^{[91]}$ showing that dissolution of ionic solutes in ILs takes place via metathesis reactions, thus resulting in an intimate mixing of the two ionic components. The observed differences in the SEM between the discharged PVdF and PIL samples can be explained by the uniform mixing and retention of sulfide species with PIL binder (in the form of ion-exchange reactions), which then influences $\mathrm{Li}_{2} \mathrm{~S}$ growth and battery cycling (Figure 6). The fluorophilic character of PVdF does not allow any of these processes to occur and thus leads to poorer cycling stability. To test the swelling and polysulfide uptake of the PIL, $0.05 \mathrm{M} \mathrm{Li}_{2} \mathrm{~S}_{2}$ in electrolyte solution was mixed with PVdF and PIL4 (Figure S-1). The green solution remained green after addition of PVdF, but turned yellow for PIL4. This color change indicates that the PIL, unlike PVdF, is an active component in the cycling process and acts as a catalyst for the disproportionation reaction of $\mathrm{Li}_{2} \mathrm{~S}_{2}$ : $3 \mathrm{~S}_{2}{ }^{2-} \leftrightarrow \mathrm{S}_{4}{ }^{2-}+2 \mathrm{~S}^{2-} \cdot{ }^{[92,93]}$

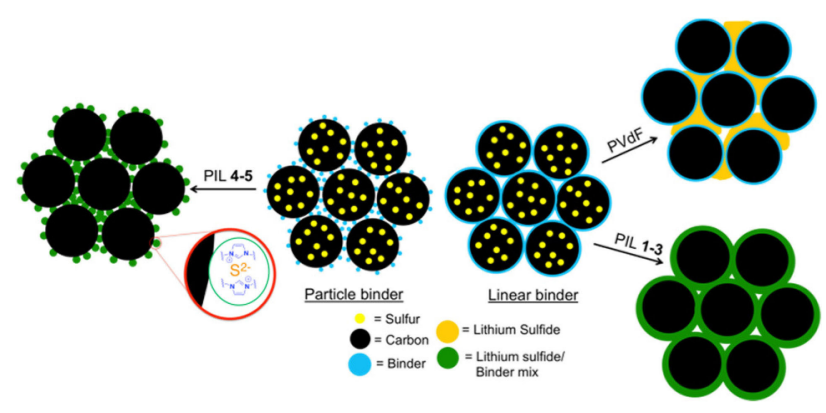

Figure 6. Schematic representation of the sulfide precipitation around and in between the binder/carbon for PVdF and PIL binders.

\subsection{Lithium Surface Passivation using Polymerized ILs}

Li-metal anode, due to its lightweight (density $0.534 \mathrm{~g} \mathrm{~cm}^{-3}$ ), low standard redox potential $\left(\mathrm{E}^{0}=-3.04 \mathrm{~V}\right.$ vs. NHE) and high theoretical specific capacity $\left(3860 \mathrm{mAhg}^{-1}\right)$, is presently being reconsidered as electrode material for rechargeable $\mathrm{Li}$ metal batteries (LMB), in particular $\mathrm{Li}-\mathrm{S}$ batteries. ${ }^{[5,94-96]}$ Although Li-metal anodes are already successfully incorporated in primary batteries, its application in rechargeable batteries, where organic solvents are used, is restricted due to numerous problems; one of them is side reactions between the surface of the anode and the electrolytes. Due to the high reactivity of Li-metal with most organic solvents, the formation of the $\mathrm{SEI}^{[97,98]}$ occurs that continuously grows and alter during cycling. ${ }^{[99]}$ In the case of carbonaceous-based negative electrode material, the SEI has a stabilizing effect by 
preventing further physical contact between the graphite anode and the organic electrolyte. ${ }^{[100]}$ For Li-metal anodes, this process continues throughout the whole cycle life consuming the electrolyte that results in serious electrode corrosion and low cycling efficiency. In order to tackle these issues, as well as to reduce the formation of lithium dendrites and, in the $\mathrm{Li}-\mathrm{S}$ system, avoid the formation of the lithium polysulfide shuttle mechanism, various solutions were considered. One of the solutions to is to prepare an artificial SEI layer, which could be stable and protect the surface of the electrode. Protective layers prepared via an in-situ method, bare the advantage of conformally contacting the surface of the Limetal anodes on a microscopic scale. ${ }^{[101]}$ The surface roughness of the Li-metal anodes is critical for the evolution of the lithium deposits and propagation of lithium dendrites.

Polymer coatings can significantly improve the electrochemical deposition of Li-metal by improving conductivity, processability and stability, resulting in enhanced lithium cycling performances. ${ }^{[102,103]}$ ILs have already shown good compatibility with the Li-metal anode ${ }^{[104]}$ and good passivation properties $^{[105]}$ by forming a stable SEI composed of the IL (cation and anion) decomposition products. ${ }^{[106]}$ Kim et al. ${ }^{[106]}$ have shown improved electrochemical performances of $\mathrm{Li}$ metal anodes that were coated with composite PIL-poly (ethylene glycol) methacrylate (POEM) passivation layer. Although the passivated electrodes exhibited larger overpotentials during the lithium electrodeposition-electrodissolution process, after more than 130 cycles these passivated Limetal anodes showed higher cycling stability compare to the non-passivated ones. Suppressed lithium dendrites formation, with a smooth surface of the cycled Li-metal anode after $400 \mathrm{~h}$ of continuous electrodissolution and electrodeposition at $0.2 \mathrm{mAcm}^{-1}$, was shown for an IL-decorated poly (methylmethacrylate) (PMMA) nanoparticles dispersed in a propylene carbonate (PC). ${ }^{[107]}$ The reason for the enhanced cycling behavior was attributed to the unique structure of the composite single-ion conductor, having a brush-like structure that provides space for both the Li-ion movement as well as grafting of anionic groups to enhance mobility. Passivated Limetal anodes using N-propyl-N-methylpyrrolidinium bis(fluorosulfonyl)imide (C3mpyrFSI) IL, have indicated that the high lithium salt concentration results in a reduction of the interfacial impedance of such electrodes and enables the lithium electrodissolution and electrodeposition at high current densities. ${ }^{[108]}$ Similarly, Li et al. ${ }^{[109]}$ have indicated that Limetal anodes passivated by N-propyl-N-methylpyrrolidinium bis(trifluoromethanesulfonyl)amide (Py13TFSI) IL together with using an optimized hybrid electrolyte remarkably increased the interfacial stability as well as the Coulombic efficiency of the lithium cycling performances. The passivation of the Li-metal surface using a hybrid electrolyte was found to be advantageous for the cycling performances of the Li-metal anodes, as increased cycle life performance and fewer short circuits with suppressed dendrites formation were exhibited. ${ }^{[10]}$
Electrochemical reduction of electrolyte additives at the surface of anode materials was proven as viable solution towards the deactivation of the organic electrolyte continuous decomposition. ${ }^{[11]}$ The suggested mechanism relies on the electrochemical reduction of molecule containing one or more carbon-carbon double bond. Similarly, ILs grafted on a polymerizable backbones lead, as a result of their polymerization, to the formation of PILs with applications in various fields. ${ }^{[25]}$ Such ILs can be easily polymerized at the Li-metal anode surface, due to its negative standard potential. Furthermore, since both the IL cation and anion participate in the formation of such insoluble passivation films, the organic and inorganic content of the decomposition products can be controlled by selectively choosing the cation and anion of the IL.

In this section, we studied the formation of insoluble decomposition products that passivates the surface of Li-metal anodes. The momomers used were (2,3-dimethyl-1-(4-vinylbenzyl)-1H-imidazol-3-ium TFSI (M3TFSI) and M3FSI (Figure 7). The goal was to attach the PIL at the surface of the Limetal anode by polymerizing the vinylene-group of the IL monomer.

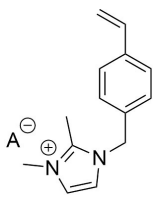

Figure 7. Chemical structure of monomer $\mathrm{M} 3$, where $\mathrm{A}^{-}=\mathrm{TFSI}^{-}$and $\mathrm{FSI}^{-}$.

The PIL coating layer was achieved by storing the Limetal anodes in the pure liquid monomers for various periods of time. Li-metal anodes were stored with M3TFSI at room temperature, and with M3FSI at $50{ }^{\circ} \mathrm{C}$. The higher storing temperature of M3FSI was required since M3FSI is solid at room temperature. Prior the storage, the Li-metal anodes were roll-pressed according to the method described by Becking et al. ${ }^{[12]}$ This method reduces in one pass both the surface roughness of pristine Li-metal anodes as well as the thickness of the native surface film. The surface native film on Li-metal anodes is formed during the extrusion process of Li-metal foil and lowers the chemical reactivity with the atmospheric gas (dry air) and increases handling. ${ }^{[13]}$ After the storage, to remove the excess of monomer, the Li-metal anodes were carefully washed with DME and dried under vacuum. We observed that after more than 1 week, white particles started to agglomerate on the surface of the Li-metal anodes. To investigate if the organic coating covers the surface of the Limetal anode, SEM investigations of the dried samples were carried out (Figure 8). The comparison between the surface morphology of the pristine Li-metal anode (Figure 8a) and the morphology of the Li-metal anodes stored in M3TFSI and M3FSI (Figure $8 \mathrm{~b}, \mathrm{c}$ ) indicate the existence of an organic film 


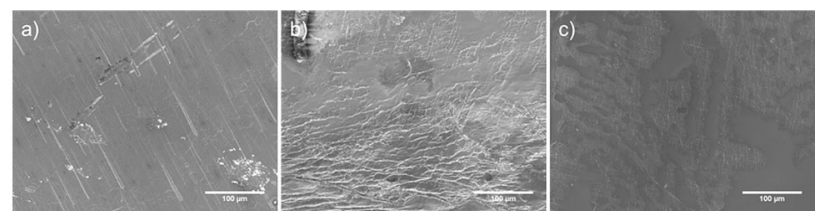

Figure 8. SEM images of the (a) pristine Li-metal anode and after storing for 7 days in (b) M3TFSI and (c) M3FSI, after washing with DME and drying under vacuum.

in nature at the surface of these electrodes, although not homogeneous in thickness and coverage. The surface of the Li-metal anodes treated with M3TFSI (Figure 8b) seems to be rougher than the surface of the Li-metal anodes treated with M3FSI (Figure 8c). Nevertheless, both M3 treated Li-metal anodes present a rougher surface morphology than the surface of the pristine Li-metal anodes. This is an indication that the M3TFSI and M3FSI monomers are reacting with the surface of the Li-metal anode and the decomposition reaction products adhere and accumulate on the surface of the electrodes.

In order to observe the chemical nature of the coating layer, ATR-IR spectrum of the pure monomer was compared to the spectrum of the Li-metal anodes, after storage for 7 days, washing and drying (Figure 9). The spectrum of the pure monomer (black line) shows the IR characteristic carboncarbon double bond (vinyl group) at around $1630 \mathrm{~cm}^{-1}$, independent of the anion. For the Li-metal anodes stored in M3TFSI (Figure 9a) and M3FSI (Figure 9b), the characteristic band of the vinyl group disappeared. These results suggest that a reductive polymerization of the vinyl group occurred within 7 days of storing the Li-metal anodes in M3-based monomers.
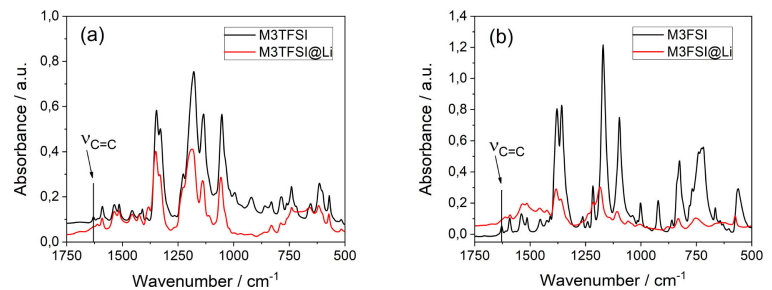

Figure 9. ATR-IR spectra of the pristine M3-based monomers (black) and spectra of Li-metal anodes (red) stored in (a) M3TFSI and (b) M3FSI, after the electrodes were washed with DME and dried under vacuum.

To assess the electrochemical performances of the Li-metal anodes passivated with the M3-based monomers, Li-symmetric cells were assembled (Figure 10a) and cycled by transferring $2.825 \mathrm{mAh} /$ cycle using a current of $0.25 \mathrm{~mA} \mathrm{~cm}^{-2}$ for the first 10 cycles (Figure 10b,c,d) and $0.5 \mathrm{mAcm}^{-2}$ for the rest of the cycling (1000 cycles). Within the initial cycles (first 10 cycles, 200 hours), the polarization voltages during the lithium electrodissolution and electrodeposition process varied as a result of the disruption of the passivating film and exposure of the fresh Li-metal surface. This is observed in the decrease of the overvoltage of the Li-symmetric cells without a protection layer and those with M3TFSI (Figure 10b,c). However, the overvoltages of the Li-metal anodes passivated by M3FSI do not show such a decrease as the more reactive FSI-anion forms a more inorganic passivation film $(\mathrm{LiF})$ rather than organic $\left(\mathrm{CF}_{3}\right)$ (Figure 10d). Additionally, the noisier voltage for the protected electrodes is possibly due to the side reactions between the coated Li-metal surface and the electrodeposited lithium. From an electrochemical performance point of view, the main difference observed between FSI- and TFSIbased M3 monomers, is that the FSI-based components build up a better protective layer. This is in agreement with literature reports indicating that a higher amount of $\mathrm{LiF}$ on the surface of the lithium-metal electrodes results in a stable electrodissolution and electrodeposition of lithium, occurring also with reduced overvoltages. ${ }^{[14]}$ Further, we can conclude that the presence of the M3FSI monomer results in the formation of passivation layer that stabilizes the cycling performances of Li-metal anodes in Li-S cells (Figure 10e) even if the overvoltages are higher due to the resistive nature of the passivation layer. The advantage of using monomers that are reductively polymerizing when in contact with the surface of the Li-metal anodes, is represented by the fact that the polymerization process occurs independently of an applied potential. In this way, the nature of the reaction products accumulating at the surface of the Li-metal anode can be decoupled from the influence of the electrolyte components and can be added as an independent treatment step in the fabrication of passivated Li-metal electrodes.

\section{Summary}

Li-S batteries have great potential for next generation of energy storage demands because of the high capacity of their electrodes. However, there are major issues associated with their application. We present here several approaches to solving some of the pressing problems, by employing ILs and their polymers in different components of the battery. ILs were used as electrolyte matrices and shown to decrease the polysulfide solubility. PILs were used as binders for the cathode in the form of linear and particle binders. They generally present cells with superior cyclability to those based on PVdF binders, and in some cases, also improved capacity. The PILs inhibited swelling-induced degradation and retained the sulfides within the cathode. The surface of a Li-metal anode can be passivated by reacting IL monomers directly with the lithium surface. The nature of the passivation film bares both organic and inorganic components due to the polymerization of the IL cation (contains the polymerizable group) and the decomposition of the anion (FSI promotes more $\mathrm{LiF}$ ). Such film is a potential approach for Li-metal surface protection. These applications altogether demonstrate some of the advantages of ILs and their derivatives in improving the performance of $\mathrm{Li}-\mathrm{S}$ batteries. 

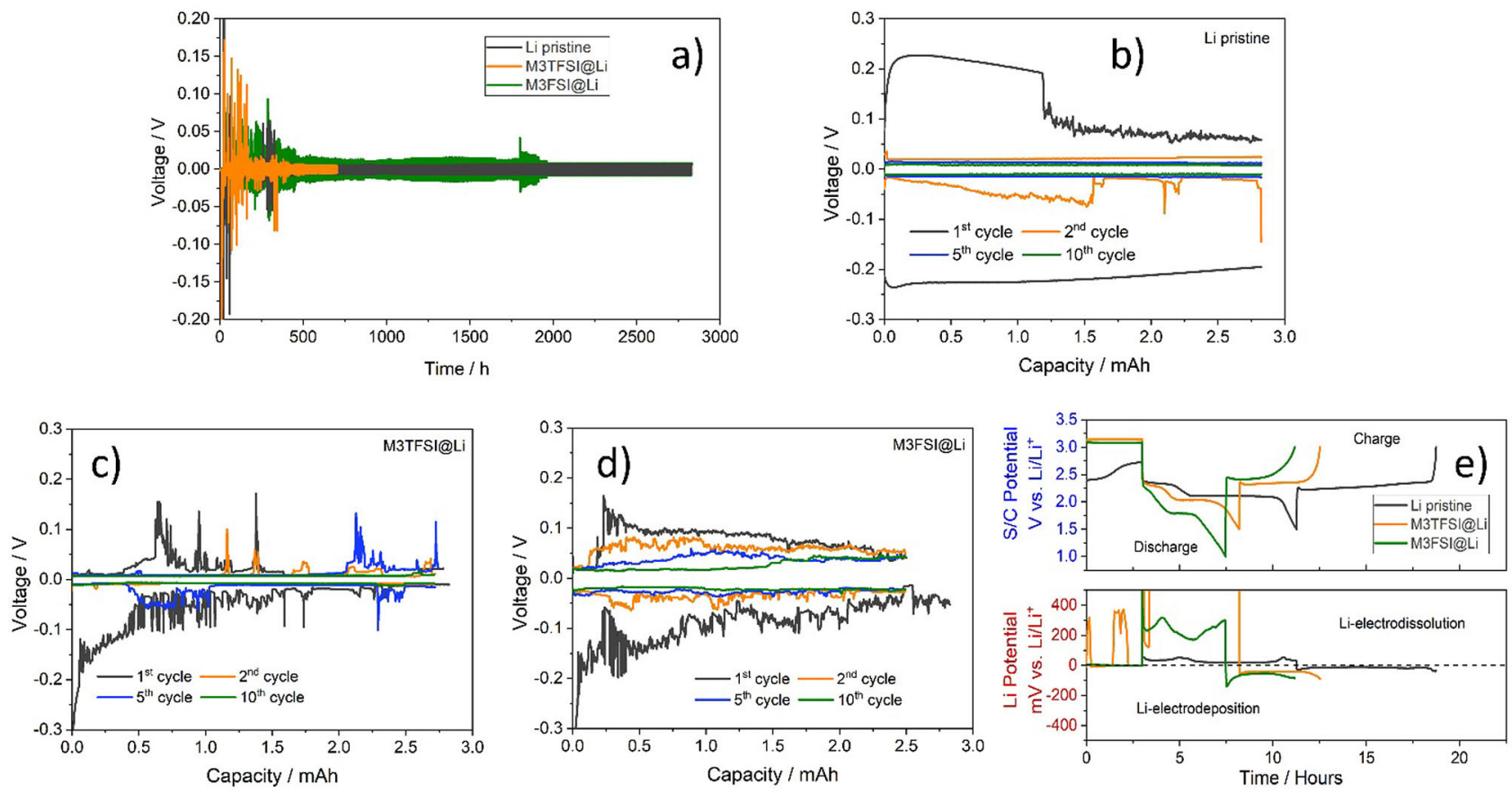

Figure 10. Comparison between (a) voltage vs. time plots of Li-symmetrical cells Li-pristine and M3-based passivated layers, (b), (c) and (d) overvoltage profiles evolution within the initial cycles $\left(10 \mathrm{~h}\right.$ with $\left.0.25 \mathrm{mAcm}^{-2}\right)$ and (e) potentials evolution within the $1^{\text {st }}$ cycle in a $\mathrm{Li}-\mathrm{S}$ cell $\left(35 \mu \mathrm{L}\right.$ electrolyte, $\left.2.5 \mathrm{mg} \mathrm{cm}^{-2}, 0.1 \mathrm{C}\right)$. In all experiments the electrolyte was $1 \mathrm{M}$ LiTFSI in DME:DOL $1: 1(\mathrm{v} / \mathrm{v})$ and the measurements were done at $20^{\circ} \mathrm{C}$ ).

\section{Permissions}

Figures 9 and 10, Table S-1 and Figure S-1 were excerpted from the original paper, ${ }^{[8]}$ which can be found at https:// pubs.acs.org/doi/abs/10.1021/acs.chemmater.8b02357. Further permissions related to the material excerpted should be directed to the ACS.

\section{Acknowledgements}

The European Union Horizon 2020 framework under Grant Agreement 666221 (HELIS) and ARRS Program P2-0393 are acknowledged for funding. Dr. Vida Lapornik is acknowledged for technical support for UV-Vis measurements. We thank the Max Planck Society, University of Münster, Chalmers University of Technology, and The National Institute of Chemistry (Slovenia) for their support.

\section{References}

[1] X.-B. Cheng, R. Zhang, C.-Z. Zhao, F. Wei, J.-G. Zhang, Q. Zhang, Adv. Sci. 2015, 3, 1500213.

[2] R. Schmuch, R. Wagner, G. Hörpel, T. Placke, M. Winter, Nat. Energy 2018, 3, 267-278.

[3] S.-H. Chung, C.-H. Chang, A. Manthiram, Adv. Funct. Mater. 2018, 28, 1801188.
[4] H. Zhao, N. Deng, J. Yan, W. Kang, J. Ju, Y. Ruan, X. Wang, X. Zhuang, Q. Li, B. Cheng, Chem. Eng. J. 2018, 347, 343-365.

[5] Y. Fan, X. Chen, D. Legut, Q. Zhang, Energy Storage Mater. 2019, 16, 169-193.

[6] E. Peled, M. Goor, I. Schektman, T. Mukra, Y. Shoval, D. Golodnitsky, J. Electrochem. Soc. 2017, 164, A5001-A5007.

[7] X. Li, X. Sun, Adv. Funct. Mater. 2018, 28, 1801323.

[8] J. Liu, Q. Zhang, Y.-K. Sun, J. Power Sources 2018, 396, 1932.

[9] Z.-L. Xu, J.-Q. Huang, W. G. Chong, X. Qin, X. Wang, L. Zhou, J.-K. Kim, Adv. Energy Mater. 2017, 7, 1602078.

[10] Y. Zhang, Z. Gao, N. Song, J. He, X. Li, Mater. Today 2018, 9, 319-335.

[11] S. Drvarič Talian, M. Bešter-Rogač, R. Dominko, Electrochim. Acta 2017, 252, 147-153.

[12] S. Waluś, G. Offer, I. Hunt, Y. Patel, T. Stockley, J. Williams, R. Purkayastha, Energy Storage Mater. 2018, 10, 233-245.

[13] Q. Pang, X. Liang, C. Y. Kwok, L. F. Nazar, Nat. Energy 2016, 1,16132

[14] S. Drvarič Talian, S. Jeschke, A. Vizintin, K. Pirnat, I. Arčon, G. Aquilanti, P. Johansson, R. Dominko, Chem. Mater. 2017, 29, 10037-10044.

[15] P. G. Bruce, S. A. Freunberger, L. J. Hardwick, J.-M. Tarascon, Nat. Mater. 2012, 11, 19-29.

[16] X.-B. Cheng, J.-Q. Huang, Q. Zhang, J. Electrochem. Soc. 2018, 165, A6058-A6072.

[17] J. Scheers, S. Fantini, P. Johansson, J. Power Sources 2014, 255, 204-218.

[18] S. Zhang, K. Ueno, K. Dokko, M. Watanabe, Adv. Energy Mater. 2015, 5, 1500117. 
[19] A. Vizintin, M. Lozinšek, R. K. Chellappan, D. Foix, A. Krajnc, G. Mali, G. Drazic, B. Genorio, R. Dedryvère, R. Dominko, Chem. Mater. 2015, 27, 7070-7081.

[20] A. Vizintin, M. U. M. Patel, B. Genorio, R. Dominko, ChemElectroChem 2014, 1, 1040-1045.

[21] A. Manthiram, Y. Fu, S.-H. Chung, C. Zu, Y.-S. Su, Chem. Rev. 2014, 114, 11751-11787.

[22] Y. Yang, G. Zheng, Y. Cui, Chem. Soc. Rev. 2013, 42, 3018.

[23] X.-B. Cheng, C. Yan, X. Chen, C. Guan, J.-Q. Huang, H.-J. Peng, R. Zhang, S.-T. Yang, Q. Zhang, Chem 2017, 2, 258-270.

[24] A. Lahiri, N. Borisenko, F. Endres, Top. Curr. Chem. 2018, 376, 9.

[25] J. Yuan, D. Mecerreyes, M. Antonietti, Prog. Polym. Sci. 2013, 38, 1009-1036.

[26] S. Livi, J. Duchet-Rumeau, J. F. Gérard, T. N. Pham, Macromol. Chem. Phys. 2015, 216, 359-368.

[27] Q. Yang, Z. Zhang, X.-G. Sun, Y.-S. Hu, H. Xing, S. Dai, Chem. Soc. Rev. 2018, 47, 2020-2064.

[28] Y. Ma, G. Ji, B. Ding, J. Y. Lee, J. Mater. Chem. A 2013, 1, 13625.

[29] J.-W. Park, K. Ueno, N. Tachikawa, K. Dokko, M. Watanabe, J. Phys. Chem. C 2013, 117, 20531-20541.

[30] A. Eftekhari, Y. Liu, P. Chen, J. Power Sources 2016, 334, 221239.

[31] J.-S. Lee, K. Sakaushi, M. Antonietti, J. Yuan, RSC Adv. 2015, $5,85517-85522$

[32] J. von Zamory, M. Bedu, S. Fantini, S. Passerini, E. Paillard, J. Power Sources 2013, 240, 745-752.

[33] A. Basile, A. I. Bhatt, A. P. O'Mullane, Nat. Commun. 2016, 7, ncomms 11794.

[34] Z. Zhang, Q. Zhang, J. Shi, Y. S. Chu, X. Yu, K. Xu, M. Ge, H. Yan, W. Li, L. Gu, Adv. Energy Mater. 2017, 7, 1601196.

[35] C. Li, L. Gu, S. Tsukimoto, P. A. van Aken, J. Maier, Adv. Mater. 2010, 22, 3650-3654.

[36] L. X. Yuan, J. K. Feng, X. P. Ai, Y. L. Cao, S. L. Chen, H. X. Yang, Electrochem. Commun. 2006, 8, 610-614.

[37] M. Barghamadi, A. S. Best, A. I. Bhatt, A. F. Hollenkamp, P. J. Mahon, M. Musameh, T. Rüther, J. Power Sources 2015, 295, 212-220.

[38] S. Jeschke, P. Johansson, Chem. Eur. J. 2017, 23, 9130-9136.

[39] J. Becking, A. Gröbmeyer, M. Kolek, U. Rodehorst, S. Schulze, M. Winter, P. Bieker, M. C. Stan, Adv. Mater. Interfaces 2017, 4, 1700166.

[40] R. Dominko, A. Vizintin, G. Aquilanti, L. Stievano, M. J. Helen, A. R. Munnangi, M. Fichtner, I. Arcon, J. Electrochem. Soc. 2018, 165, A5014-A5019.

[41] E. Peled, I. Shekhtman, T. Mukra, M. Goor, I. Belenkaya, D. Golodnitsky, J. Electrochem. Soc. 2018, 165, A6051-A6057.

[42] V. Thangavel, K.-H. Xue, Y. Mammeri, M. Quiroga, A. Mastouri, C. Guéry, P. Johansson, M. Morcrette, A. A. Franco, J. Electrochem. Soc. 2016, 163, A2817-A2829.

[43] L. Suo, Y.-S. Hu, H. Li, M. Armand, L. Chen, Nat. Commun. 2013, 4, 1481-1490.

[44] C. Barchasz, J.-C. Leprêtre, S. Patoux, F. Alloin, Electrochim. Acta 2013, 89, 737-743.

[45] C. Barchasz, J.-C. Leprêtre, S. Patoux, F. Alloin, J. Electrochem. Soc. 2013, 160, A430-A436.

[46] A. Hayashi, R. Ohtsubo, T. Ohtomo, F. Mizuno, M. Tatsumisago, J. Power Sources 2008, 183, 422-426.

[47] J. Kazem, G. Mahmoudreza, P. Chen, J. Mater. Chem. A 2013, 1, 2769-2772.

[48] Z. Wei Seh, W. Li, J. J. Cha, G. Zheng, Y. Yang, M. T. McDowell, P.-C. Hsu, Y. Cui, Nat. Commun. 2013, 4, 1331.
[49] M.-K. Song, E. J. Cairns, Y. Zhang, Nanoscale 2013, 5, 21862204.

[50] T. Lin, Y. Tang, Y. Wang, H. Bi, Z. Liu, F. Huang, X. Xie, M. Jiang, Energy Environ. Sci. 2013, 6, 1283-1290.

[51] M. Armand, F. Endres, D. R. MacFarlane, H. Ohno, B. Scrosati, Nat. Mater. 2009, 8, 621-629.

[52] Y. Lu, S. K. Das, S. S. Moganty, L. A. Archer, Adv. Mater. 2012, 24, 4430-4435.

[53] H. Niedermeyer, J. P. Hallett, I. J. Villar-garcia, P. A. Hunt, T. Welton, Chem. Soc. Rev. 2012, 41, 7780-7802.

[54] J. Wang, S. Y. Chew, Z. W. Zhao, S. Ashraf, D. Wexler, J. Chen, S. H. Ng, S. L. Chou, H. K. Liu, Carbon 2008, 46, 229-235.

[55] K. Ueno, J. Park, A. Yamazaki, T. Mandai, N. Tachikawa, K. Dokko, M. Watanabe, J. Phys. Chem. C 2013, 117, 2050920516.

[56] N. Tachikawa, K. Yamauchi, E. Takashima, J.-W. Park, K. Dokko, M. Watanabe, Chem. Commun. 2011, 47, 8157-8159.

[57] J. Park, K. Yamauchi, E. Takashima, N. Tachikawa, K. Ueno, K. Dokko, M. Watanabe, J. Phys. Chem. C 2013, 117, 4431-4440.

[58] S. Kim, Y. Jung, S.-J. Park, J. Power Sources 2005, 152, 272 277.

[59] S. Kim, Y. Jung, S.-J. Park, Electrochim. Acta 2007, 52, 21162122.

[60] J. H. Shin, E. J. Cairns, J. Electrochem. Soc. 2008, 155, A368A373.

[61] L. Wang, H. R. Byon, J. Power Sources 2013, 236, 207-214.

[62] K. Dokko, N. Tachikawa, K. Yamauchi, M. Tsuchiya, a. Yamazaki, E. Takashima, J.-W. Park, K. Ueno, S. Seki, N. Serizawa, J. Electrochem. Soc. 2013, 160, A1304-A1310.

[63] J.-W. Choi, J.-K. Kim, G. Cheruvally, J.-H. Ahn, H.-J. Ahn, K.W. Kim, Electrochim. Acta 2007, 52, 2075-2082.

[64] F. Wu, J. Chen, L. Li, T. Zhao, R. Chen, J. Phys. Chem. C 2011, 115, 24411-24417.

[65] S. Kim, Y. Jung, H. S. Lim, Electrochim. Acta 2004, 50, 889 892.

[66] X. Liang, Z. Wen, Y. Liu, H. Zhang, J. Jin, M. Wu, X. Wu, J. Power Sources 2012, 206, 409-413.

[67] F. Wu, Q. Zhu, R. Chen, N. Chen, Y. Chen, Y. Ye, J. Qian, L. Li, J. Power Sources 2015, 296, 10-17.

[68] F. Wu, Q. Zhu, R. Chen, N. Chen, Y. Chen, L. Li, Electrochim. Acta 2015, 184, 356-363.

[69] Y. Yan, Y. Yin, S. Xin, J. Su, Y. Guo, L. Wan, Electrochim. Acta 2013, 91, 58-61.

[70] Z. J. Chen, T. Xue, J.-M. Lee, RSC Adv. 2012, 2, 10564-10574.

[71] Y. Jin, S. Fang, L. Yang, S. Hirano, K. Tachibana, J. Power Sources 2011, 196, 10658-10666.

[72] S. Fang, Y. Tang, X. Tai, L. Yang, K. Tachibana, K. Kamijima, J. Power Sources 2011, 196, 1433-1441.

[73] A. Shirai, K. Fujii, S. Seki, Y. Umebayashi, S. Ishiguro, Y. Ikeda, Anal. Sci. 2008, 24, 1291-1296.

[74] Y. Umebayashi, S. Mori, K. Fujii, S. Tsuzuki, S. Seki, K. Hayamizu, S. Ishiguro, J. Phys. Chem. B 2010, 114, 6513-6521.

[75] M. U. M. Patel, R. Demir-Cakan, M. Morcrette, J.-M. Tarascon, M. Gaberscek, R. Dominko, ChemSusChem 2013, 6, 11771781.

[76] M. U. M. Patel, R. Dominko, ChemSusChem 2014, 7, 21672175.

[77] C. V. Amanchukwu, J. R. Harding, Y. Shao-Horn, P. T. Hammond, Chem. Mater. 2015, 27, 550-561.

[78] I. Kovalenko, B. Zdyrko, A. Magasinski, B. Hertzberg, Z. Milicev, R. Burtovyy, I. Luzinov, G. Yushin, Science 2011, 334, 75-9. 
[79] S.-J. Park, H. Zhao, G. Ai, C. Wang, X. Song, N. Yuca, V. S. Battaglia, W. Yang, G. Liu, J. Am. Chem. Soc. 2015, 137, 25652571.

[80] S. Komaba, Y. Matsuura, T. Ishikawa, N. Yabuuchi, W. Murata, S. Kuze, Electrochem. Commun. 2012, 21, 65-68.

[81] G. B. Appetecchi, G.-T. Kim, M. Montanino, M. Carewska, R. Marcilla, D. Mecerreyes, I. De Meatza, J. Power Sources 2010, 195, 3668-3675.

[82] M. Kerner, P. Johansson, M. Kerner, P. Johansson, Batteries 2018, 4, 10.

[83] J. Yuan, S. Prescher, K. Sakaushi, M. Antonietti, J. Mater. Chem. A 2015, 3, 7229-7234.

[84] M. Baloch, A. Vizintin, R. K. Chellappan, J. Moskon, D. Shanmukaraj, R. Dedryvère, T. Rojo, R. Dominko, J. Electrochem. Soc. 2016, 163, A2390-A2398.

[85] H. Su, C. Fu, Y. Zhao, D. Long, L. Ling, B. M. Wong, J. Lu, J. Guo, ACS Energy Lett. 2017, 2, 2591-2597.

[86] L. Li, T. A. Pascal, J. G. Connell, F. Y. Fan, S. M. Meckler, L. Ma, Y.-M. Chiang, D. Prendergast, B. A. Helms, Nat. Commun. 2017, 8, 2277.

[87] A.-L. Pont, R. Marcilla, I. De Meatza, H. Grande, D. Mecerreyes, J. Power Sources 2009, 188, 558-563.

[88] A. Vizintin, R. Guterman, J. Schmidt, M. Antonietti, R. Dominko, Chem. Mater. 2018, 30, 5444-5450.

[89] R. Dominko, M. U. M. Patel, V. Lapornik, A. Vizintin, M. Koželj, N. N. Tušar, I. Arčon, L. Stievano, G. Aquilanti, J. Phys. Chem. C 2015, 119, 19001-19010.

[90] M. Kavčič, K. Bučar, M. Petric, M. Žitnik, I. Arčon, R. Dominko, A. Vizintin, J. Phys. Chem. C 2016, 120, 2456824576.

[91] M. Y. Lui, L. Crowhurst, J. P. Hallett, P. A. Hunt, H. Niedermeyer, T. Welton, Chem. Sci. 2011, 2, 1491.

[92] D. Moy, A. Manivannan, S. R. Narayanan, J. Electrochem. Soc. 2015, 162, A1-A7.

[93] M. Wild, L. O’Neill, T. Zhang, R. Purkayastha, G. Minton, M. Marinescu, G. J. Offer, Energy Environ. Sci. 2015, 8, 34773494.

[94] W. Xu, J. Wang, F. Ding, X. Chen, E. Nasybulin, Y. Zhang, J. G. Zhang, Energy Environ. Sci. 2014, 7, 513-537.

[95] H. Kim, G. Jeong, Y. U. Kim, J. H. Kim, C. M. Park, H. J. Sohn, Chem. Soc. Rev. 2013, 42, 9011-9034.

[96] X. B. Cheng, R. Zhang, C. Z. Zhao, Q. Zhang, Chem. Rev. 2017, 117, 10403-10473.
[97] H. Schranzhofer, J. Bugajski, H. J. Santner, C. Korepp, K. C. Möller, J. O. Besenhard, M. Winter, W. Sitte, J. Power Sources 2006, 153, 391-395.

[98] M. Winter, Z. Phys. C 2009, 223, 1395-1406.

[99] X.-B. Cheng, R. Zhang, C.-Z. Zhao, F. Wei, J.-G. Zhang, Q. Zhang, Adv. Sci. 2015, 3, 1500213.

[100] J. O. Besenhard, M. Winter, J. Yang, W. Biberacher, J. Power Sources 1995, 54, 228-231.

[101] K. Liu, A. Pei, H. R. Lee, B. Kong, N. Liu, D. Lin, Y. Liu, C. Liu, P. chun Hsu, Z. Bao, J. Am. Chem. Soc. 2017, 139, 48154820.

[102] Y. An, Z. Zhang, H. Fei, X. Xu, S. Xiong, J. Feng, L. Ci, J. Power Sources 2017, 363, 193-198.

[103] G. A. Umeda, E. Menke, M. Richard, K. L. Stamm, F. Wudl, B. Dunn, J. Mater. Chem. 2011, 21, 1593-1599.

[104] L. Grande, E. Paillard, G.-T. Kim, S. Monaco, S. Passerini, Int. J. Mol. Sci. 2014, 15, 8122-8137.

[105] A. Basile, A. I. Bhatt, A. P. O’Mullane, Nat. Commun. 2016, 7, ncomms11794.

[106] J. Zheng, M. Gu, H. Chen, P. Meduri, M. H. Engelhard, J. G. Zhang, J. Liu, J. Xiao, J. Mater. Chem. A 2013, 1, 8464-8470.

[107] Y. Li, K. W. Wong, Q. Dou, K. M. Ng, J. Mater. Chem. A 2016, 4, 18543-18550.

[108] H. Yoon, P. C. Howlett, A. S. Best, M. Forsyth, D. R. MacFarlane, J. Electrochem. Soc. 2013, 160, A1629-A1637.

[109] N.-W. Li, Y.-X. Yin, J.-Y. Li, C.-H. Zhang, Y.-G. Guo, Adv. Sci. 2016, 4, 1600400.

[110] Y. Lu, K. Korf, Y. Kambe, Z. Tu, L. A. Archer, Angew. Chem. Int. Ed. 2013, 53, 488-492.

[111] S. S. Zhang, J. Power Sources 2006, 162, 1379-1394.

[112] J. Becking, A. Gröbmeyer, M. Kolek, U. Rodehorst, S. Schulze, M. Winter, P. Bieker, M. C. Stan, Adv. Mater. Interfaces 2017, 4, 1700166.

[113] K. Kanamura, in Encycl. Electrochem. Power Sources (Eds.: J. Garche, C. K. Dyer, P. T. Moseley, Z. Ogumi, D. A. J. Rand, B. Scrosati), Elsevier Science Ltd, 2009, p. 4538.

[114] J. Lang, Y. Long, J. Qu, X. Luo, H. Wei, K. Huang, H. Zhang, L. Qi, Q. Zhang, Z. Li, Energy Storage Mater. 2019, 16, 85-90.

Manuscript received: November 13, 2018 Revised manuscript received: February 12, 2019 Version of record online: March 5, 2019 